\title{
Information Content of Millimeter-Wave Observations for Hydrometeor Properties in Mid-Latitudes
}

\author{
Mario Mech, Susanne Crewell, Member, IEEE, Ingo Meirold-Mautner, \\ Catherine Prigent, and Jean-Pierre Chaboureau
}

\begin{abstract}
For future remote sensing applications the potential of the millimeter wavelength range for precipitation observations from geostationary orbits is investigated. Therefore, a database consisting of hydrometeor profiles from various mid-latitude precipitation cases over Europe and corresponding simulated brightness temperatures at $\mathbf{1 8}$ microwave frequencies was built using the cloud resolving model Méso-NH and the radiative transfer model MicroWave MODel. The information content of the database was investigated by applying simple statistical methods, as well as developing first-order retrieval approaches. The results show that, particularly for snow and graupel, the total column content can be retrieved accurately with relative errors smaller than $25 \%$ in dominantly stratiform precipitation cases over land and ocean surfaces. The performance for rain-water path is similar to the one for graupel and snow in light precipitation cases. For the cases with higher precipitation amounts, the relative errors for rain-water path are larger particularly over land. The same behavior can be seen in the surface rain rate retrieval with the difference that the relative errors are doubled in comparison to the rain-water path. Algorithms with reduced number of frequencies show that window channels at higher frequencies are important for the surface rain rate retrieval because these are sensitive to the scattering in the ice phase related to the rain below. For the frozen hydrometeor retrieval, good results can be achieved by retrieval algorithms based only on frequencies at $150 \mathrm{GHz}$ and above which are suitable for geostationary applications due to their reduced demands concerning the antenna size.
\end{abstract}

Index Terms-Hydrometeor, millimeter wave radiometry, remote sensing, retrieval, satellite applications.

\section{INTRODUCTION}

$\mathbf{P}$ RECIPITATION results from a complex chain of processes implicating a high variability in space and time. Therefore, the observation of precipitation with a sufficient temporal and spatial resolution for many applications, such as numerical weather forecast models or hydrological purposes, is still a challenging task.

Manuscript received June 6, 2006; revised April 4, 2007. This work was supported by EUMETSAT under Contract EUM/CO/04/1311/KJG ("Simulation study of precipitating clouds from geostationary orbits with passive microwaves").

M. Mech and S. Crewell are with the Institute for Geophysics and Meteorology, University of Cologne, 50923 Cologne, Germany (e-mail: mech@meteo.uni-koeln.de).

I. Meirold-Mautner and C. Prigent are with the LERMA, l'Observatoire de Paris, 75014 Paris, France.

J.-P. Chaboureau is with the Laboratoire d'Aérologie, Université Paul Sabatier and CNRS, 31400 Toulouse, France.

Digital Object Identifier 10.1109/TGRS.2007.898261
Traditional precipitation observation systems such as rain gauges measure precipitation at single points, mostly as accumulated daily sums with an unsatisfactory coverage particularly over ocean. In well-developed countries ground-based radar networks provide precipitation observations with a temporal resolution of about $5 \mathrm{~min}$ over large areas with high spatial resolution. Relating the measured reflectivities of the radar sampling volume to the surface rain rate can lead to substantial errors of the order of a factor of 2 [1], particularly at distances larger than $100 \mathrm{~km}$. Due to the different error factors involved in the measurement process, a homogeneous quality radar precipitation composite will not be available in the near future, even for Europe.

With satellite-based observations in the lower microwave regions promising results were accomplished over ocean from polar orbiters (see [2] and [3]). Their algorithms for retrieving precipitation rates use frequencies below $40 \mathrm{GHz}$ and are based on the brightness temperature increase through emission by the precipitation layer over the radiatively cold ocean. An algorithm applicable over ocean surfaces, including the emission signal and the information contained in the signal influenced by scattering by frozen hydrometeors above the precipitating layer, was developed by Bauer and Schlüssel [4]. By using window channels, the surface rain rate and also the hydrometeor profiles were retrieved (see [5] or [6]). Over land, the emissionbased approach is not useful, since land surface emissivity is too large and heterogeneous within the radiometer footprint. Therefore, to reduce the sensitivity to surface emissivity, higher frequencies are applied. In the millimeter wavelength region, information can be gained by examining the signal originating in the precipitating layer and modulated by scattering by large frozen hydrometeors above. Since the formation of precipitation in the mid-latitudes mostly follows the cold rain process in the solid form as snow and graupel which melts to rain at lower altitudes, there is a relation between the microwave signal originating in the upper atmospheric ice layer and the surface rain rate. This indirect approach was implemented for the 85.5-GHz window channel in various algorithms (see [7]-[12]).

The potential of millimeter $(30-300 \mathrm{GHz})$ and submillimeter-wave $(300+\mathrm{GHz})$ channels for passive spaceborne remote sensing of the troposphere and lower stratosphere has been numerically investigated by Gasiewski [13]. He found that high-frequency window channels (340 or $410 \mathrm{GHz}$ ) show a potential for observing clouds with very low liquid water contents and that these high frequencies can map thick clouds 
and precipitation with lower brightness temperature variations than lower window channels.

The scattering properties of cirrus clouds at higher submillimeter-wave frequencies up to $880 \mathrm{GHz}$ has been investigated by Evans et al. [14]. By considering the brightness temperature depression in dependence of different size distributions, particle shapes and atmospheric profiles they found that above $500 \mathrm{GHz}$ an adequate potential of sensing cirrus cloud properties exists and that the modeled brightness temperature depression is proportional to the ice water path.

Instead of using window frequencies, the use of sounding channels has been proposed by various authors. Methods dealing with sounding channels are based on the differential absorption at channels with similar weighting functions along absorption features. Either channels along the two oxygen complexes near 60 and $118 \mathrm{GHz}([15]-[17])$ are used or a combination of the $60-\mathrm{GHz}$ oxygen complex and the $183-\mathrm{GHz}$ water-vapor line [18]. These methods use the fact that the impact on brightness temperature through scattering by hydrometeors increases with frequency. This scattering signal can be extracted from the total extinction since the temperature and water-vapor dependent gaseous absorption at several sounding channels is known. Due to attenuation by oxygen or water vapor, the principal advantage of observations in the opaque bands is the almost complete elimination of the surface effects. A disadvantage of these methods is their dependence on the knowledge of the temperature profile, and the vertical distribution of the water vapor.

The development of retrieval algorithms for rain rates or hydrometeor properties requires a set of brightness temperatures with concurrent quantities. The approach of coupling cloud resolving and radiative transfer models is thereby a method used frequently to generate such data sets (for example [19]-[21]).

A method based on a variational framework using a priori information on the cloud, atmosphere and surface states from the European Center for Medium-Range Weather Forecasts (ECMWF) short-range forecasts is proposed by Bauer et al. [22]. In this paper, which was carried out to estimate the retrieval accuracy for the European contribution for the Global Precipitation Mission (EGPM) [21], window and temperature sounding channels for precipitation and hydrometeor profile retrieval were investigated. Therefore, four selected cases in the mid-to-high-latitudes over North America with weak-tomoderate precipitation intensities with significant snow amount were selected. They showed that using sounding channels for the retrieval is more stable, more accurate and less biased than using window channels. This is particularly true for snow, cloud water and hydrometeor retrievals, in general over land surfaces.

Precipitation observations over large areas with high temporal resolution should in principle be possible by geostationary satellite observations. Because current technology limits the satellite antenna to about $3 \mathrm{~m}$, the low microwave frequencies currently used on polar orbiters for precipitation observation would lead to large and unacceptable footprints $(>50 \mathrm{~km})$. In order to achieve a sufficient horizontal resolution for future hydrological and meteorological applications higher microwave frequencies could be used. For example, the horizontal resolu- tion achievable with receivers on a satellite in a geostationary orbit at a frequency of $183 \mathrm{GHz}$ is $24 \mathrm{~km}$, at $380 \mathrm{GHz}$ is $12 \mathrm{~km}$, and at $425 \mathrm{GHz}$ is $10 \mathrm{~km}$.

As preparation for such future satellite missions the potential for precipitation retrieval from observations in the millimeter and submillimeter wavelength region from geostationary orbits is investigated. Therefore, realistic simulations with a cloud resolving model combined with radiative transfer calculations for relevant frequencies are performed. To our knowledge such investigations were not carried out for the European midlatitudes so far. Other studies concentrating on the mid- to high-latitudes used models with coarser resolution and less detailed cloud microphysics, for example Bauer et al. [22] used a horizontal resolution of $40 \mathrm{~km}$ and 60 vertical levels. Hence, the created database consisting of hydrometeor profiles, together with simulated brightness temperatures for the midlatitudes is unique.

Based on this database, we investigate the potential that higher millimeter waves provide for hydrometeor observations in the mid-latitudes. In Section II, the simulation framework is presented, consisting of the mesoscale cloud model Méso-NH and the radiative transfer model MicroWave MODel (MWMOD), used to generate the database of hydrometeor profiles and corresponding brightness temperatures for the frequency selection. An overview of the five simulated midlatitude cases is given in Section III followed by an analysis of the simulated brightness temperatures (Section IV). The performance of simple retrieval algorithms, together with investigations concerning frequency combinations, reduction of the frequency number and tests of whether the database contains enough variability are demonstrated in Section V. A summary and some conclusions are given in the final Section VI of this paper.

\section{Simulation FramewORK}

\section{A. Cloud Model}

The model used to simulate the atmospheric state for the setup of the mid-latitude database of hydrometeor profiles and corresponding brightness temperatures at different microwave frequencies is the nonhydrostatic mesoscale model Méso- $\mathrm{NH}$, jointly developed by Météo-France and the Centre National de la Recherche Scientifique. A detailed description of the model is given in Lafore et al. [23]. The quality of the cloud scheme used in Méso-NH was assessed by using spaceborne sensors at various wavelengths in many investigations [24][30] showing that neither strong nor systematic deficiencies in the microphysical scheme on the prediction of the precipitating hydrometeor contents are present.

For the simulations used in this paper the mesoscale model was initialized and fed at the boundaries with 6-h analyses from the ECMWF model. To match with the footprint size of geostationary satellites at $425 \mathrm{GHz}$, the horizontal resolution of the simulations was set to $10 \mathrm{~km}$. With this horizontal resolution and for typical observation angles of approximately $50^{\circ}$ in the mid-latitudes for a geostationary orbit, only the atmospheric column above the observed grid point contributes to the simulated signal and therefore no slant path correction is necessary. 
The vertical resolution was set to 50 layers between the surface and the model top at $20 \mathrm{~km}$. The mixed-phase microphysical scheme of Méso-NH was developed by Pinty and Jabouille [31] and is based on the approach of Lin et al. [32]. It predicts the evolution of the mixing ratio of five hydrometeor categories, cloud droplets, rain drops, pristine ice crystals, snowflakes, and graupel.

Each broad particle category is characterized by intrinsic aerodynamic properties and encompasses the great variety of hydrometeors found in natural clouds. The temporal and spatial evolution of the microphysical fields results from many microphysical processes (aggregation, riming, vapor deposition, evaporation, fallout, etc.) which mostly depend on the particle size. More details such as the assumptions on the drop size distributions can be found in Meirold-Mautner et al. [27] and Wiedner et al. [28].

\section{B. Radiative Transfer Model}

The radiative transfer model MWMOD [33] solves the vector radiative transfer equation for the first two Stokes components. For this purpose, the successive order of scattering method in a plane-parallel 1-D atmosphere is applied. A set of propagation directions (nine angles per hemisphere used as nodes for the Gaussian quadrature) is used for the directional discretization of the radiation field. Absorption by atmospheric gases is calculated according to Liebe et al. [34]. A comparison with the gas absorption model by Pardo et al. [35] has been performed, indicating significant differences up to $3 \mathrm{~K}$ only in cloud free conditions (compare Section II-C). The single scattering properties of hydrometeors are computed with the extended boundary condition method T-matrix code from Mishchenko et al. [36]. Although this method can handle nonspherical particles that have an additional symmetry to their plane of rotation, we only considered spheres in this paper, not only because of computational costs, but rather because the shape distribution of ice crystals and graupel is rather uncertain and additional errors could be induced.

As the lower boundary condition the radiative transfer code requires the surface emissivity. For continental surfaces, emissivity maps calculated from satellite observations up to $90 \mathrm{GHz}$ by Prigent et al. [37] serve as input to MWMOD. Since the variability of the surface emissivity at frequencies higher than $90 \mathrm{GHz}$ is negligible, the one at $90 \mathrm{GHz}$ is used for higher frequencies as well. Over the ocean the FAST EMissivity model (FASTEM) by English and Hewison [38] was included to calculate the emissivity depending on the 10-m wind speed and the sea surface temperature.

Although, the model provides the simulated brightness temperatures for all nine Gaussian angles for up and downward looking geometry, in the following only the simulations of the total intensity for a downward observation angle of $51.8^{\circ}$ were evaluated in this paper, being appropriate for a geostationary satellite observing Europe.

\section{Coupling of the Models}

When interfacing the mesoscale model output with the radiative transfer model, the hydrometeor properties (size and shape distribution, phase, densities, and dielectric properties) need to be carefully matched to avoid any inconsistencies of microphysical parameterizations. Therefore, the direct output of Méso-NH, e.g., the bulk specific hydrometeor content of one grid cell needs to be distributed to the different drop diameters using the same assumptions as used in the microphysical parameterizations of Méso-NH. A critical point here is the discretization of the particle diameter. Using too few size bins can lead to inaccuracies particularly for strong variations of the Mie-Parameter, defined as $\chi=\pi D / \lambda$, where $D$ is the particle diameter and $\lambda$ the wavelength of interest. In contrast, using too many bins increases the computation time heavily. Sensitivity studies showed that for frequencies most sensitive to changes in number of size bins, the brightness temperature changes for an increase from 4 to 10 are not larger than $1 \mathrm{~K}$. A further increase of the number of size bins has no significant effect on the accuracy of the brightness temperature calculations. On the other hand, for this increase in number of size bins and a relatively small gain of accuracy, the computation time doubles. Hence, like in Wiedner et al. [28], four different diameters, i.e., $1 / 4,3 / 4,1.5$, and 3 times the modal diameter, are used for the discretization of the snow, graupel and rain distributions with a diameter dependent mass and density. Since cloud droplets and ice cloud particles are small compared to the wavelength of interest, monodisperse distributions are considered with fixed densities of 1 and $0.92 \mathrm{~g} \cdot \mathrm{cm}^{-3}$, respectively. The settings for the mass and the density are consistent with those in the microphysical scheme of Méso-NH.

For the calculation of the scattering properties of the five hydrometeor types in the model, appropriate dielectric properties need to be considered. The liquid particles like rain and clouds are therefore described by the relation given by Manabe et al. [39]. For ice the refractive index is taken from Warren [40]. Skofronick-Jackson et al. [41] describe the Maxwell-Garnett mixing formula that is used for the calculation of the refractive index for snow and graupel. A sensitivity study investigating the impact of different descriptions of the dielectric properties is given in Meirold-Mautner et al. [27].

Note that the $T_{b}$ results achieved with MWMOD are similar to those obtained using Méso-NH in combination with the radiative transfer models described by Meirold-Mautner et al. [27] and Wiedner et al. [28]. The maximum $3 \mathrm{~K}$ difference is attributed to the different gas absorption models used in each radiative transfer calculation. In the latter one, the gas absorption is according to Pardo et al. [35], whereas the gas absorption model after Liebe et al. [34] is used in MWMOD. For a more detailed description of the difference between different gas absorption models, see Melsheimer et al. [42]. Because the differences in cloudy scenes are negligible, the uncertainty of the gas absorption model is not considered to be relevant for this paper.

\section{Frequency Selection}

The question of whether window frequencies or frequencies in the various absorption bands are best suited for precipitation retrieval is still under discussion. In window channels, the information comes from the scattering by the hydrometeors 
TABLE I

List of Frequencies CONSIDERED IN THIS STUdy BETWEEN 50 AND 428.76 GHz Relevant For Planned SATEllite Missions

\begin{tabular}{|c|c|}
\hline $\begin{array}{c}50.3,52.8,53.6, \\
54.5,54.94,55.5\end{array}$ & $\mathrm{O}_{2}$ complex between 50 and $60 \mathrm{GHz}$ \\
\hline $110.65,115.25,116.65$, & $\mathrm{O}_{2}$ line at $118 \mathrm{GHz}$ \\
$117.25,117.65,118.0$ & \\
\hline $\begin{array}{c}89.0,150.0,176.31, \\
340.0,398.2,428.76\end{array}$ & window frequencies \\
\hline
\end{tabular}

and provides only integrated quantities. The use of absorption channels provides the possibility of vertically resolving the atmospheric hydrometeor profile to some extent. By applying the method of differential absorption between frequencies in the oxygen line complex between $50-60 \mathrm{GHz}$ and the line at $118 \mathrm{GHz}$ [22], promising results for precipitation retrieval were obtained.

In this paper, the selection of the frequency bands is based on the ones that are currently investigated for possible use in future satellite missions, on those relevant to the European contribution to the EGPM and in heritage of successful satellite missions like the advanced microwave sounding unit (AMSU).

The 18 selected frequencies in the oxygen absorption complex between 50-60 and $118 \mathrm{GHz}$, and the selected window channels in the range between 89 and $428.76 \mathrm{GHz}$ are compiled in Table I. Above $200 \mathrm{GHz}$, only three window frequencies are included as sounding channels since these high frequencies are not likely to be flown on satellites in the near future.

\section{Simulated CASES}

To cover different precipitation situations for the midlatitudes in different seasons, a set of five different cases was selected. In order to take into account the microphysical changes occurring in the lifetime of precipitation events, two different time steps were chosen for each event. Table II shows that at different time steps, significant differences in maximum and minimum rain rates, as well as in the partitioning of the different hydrometeor contents occur. The simulated cases include a light frontal precipitation event during September 2001 at Hoek van Holland and a Winter front over the Rhine area in 2000. For cases with strong rain rates, the Algiers flood of 2001, the Elbe flood of 2002, and the Millennium Storm in England (2000) are included. The areal distribution of the precipitation and the extent of the simulation area are described in terms of maps of surface rain rates in Fig. 1. That this set of simulated cases covers a reasonable number of heterogeneous precipitation types can be seen in Table II.

Since the surface rain rates are the product of a number of complex processes, the relation between the rain rate and the hydrometeors aloft, which determine the microwave signal, is not a straightforward one. The mean vertical profiles of the hydrometeors for the Hoek van Holland case (Fig. 2) show that the liquid layers are confined in the lower $2 \mathrm{~km}$ of the atmosphere with the frozen particles on top. This makes clear that the precipitation is produced by the cold rain process in the solid form as snow and graupel which melts at lower altitudes to rain. The explicit inclusion of the melting effect in modeled brightness temperatures as proposed by Bauer $e t$ al. [43], is not necessary in our investigations. They showed that for frequencies above $37 \mathrm{GHz}$ only minor changes in modeled brightness temperatures are to be expected, which furthermore are obscured by the hydrometeors above. A similar separation of the different phases is present in the other events, with shifted height of the boundary between liquid and frozen parts, depending on the vertical temperature profiles. The separation of the different phases raises the hope that the microwave signal, which will be mainly determined by the upper atmospheric ice particles, will have an accurate relation to the surface rain rate. This hope is encouraged by the fact that there are correlations up to 0.7 , depending on case and time step, between integrated frozen hydrometeor content (snow, graupel, and ice) and surface rain rate [44].

A more detailed description of the simulated cases and the setup of Méso-NH for the single model runs can be found in Chaboureau et al. [26].

\section{AnAlysis of Simulated BRIGHTNESS TEMPERATURES}

The brightness temperature maps shown in Fig. 3 give an impression which atmospheric properties might be retrieved. The highest frequencies of the two oxygen absorption bands $(55.5$ and $118 \mathrm{GHz})$ are highly opaque and only provide information on the upper tropospheric temperature. With decreasing frequency the radiation stems from lower altitudes. Consequently, the lowest channels $(50.3$ and $110.65 \mathrm{GHz})$ are already located in window regions and show the surface contribution with strong contrast due to strong differences in the emissivity $\epsilon$ between land $(\epsilon \approx 0.9)$ and ocean $(\epsilon \approx 0.5)$. With increasing frequency, emission and scattering by hydrometeors evolve differently. The increase of extinction due to small particles, like cloud droplets, is approximately twice as strong at frequencies in the $118-\mathrm{GHz}$ oxygen complex than at the corresponding (meaning similar clear air weighting function) frequencies in the 60-GHz complex [16]. For this reason, these channels, which are usually used for temperature sounding, were proposed by Bauer and Mugnai [15] for remote sensing of precipitation.

At higher frequency channels, e.g., the $176.31 \mathrm{GHz}$ (wing of $\mathrm{H}_{2} \mathrm{O}$-line) and above, the atmospheric absorption is already so strong, that land/ocean differences disappear (see Fig. 3) and the brightness temperature structures are closely related to the water-vapor field (not shown). Due to high scattering by frozen hydrometeors, the ice cloud band over western Germany can be detected well by strongly reduced brightness temperatures.

Skofronick-Jackson et al. [45] showed that there is a high surface contribution to the brightness temperature for AMSUB window channels at 89 and $150 \mathrm{GHz}$. This can be half of the observed signal at $89 \mathrm{GHz}$ for profiles with low frozen hydrometeor contents over land. This effect decreases with increasing hydrometeor contents. This strong contribution of the land surfaces to the brightness temperature can be seen in the brightness temperature maps (Fig. 3), that expose a strong difference of land and ocean pixels at window frequencies and 
TABLE II

Hydrometeor Statistics for All Cases: Number of Profiles, Maximum Precipitation Rate $\left(i_{\text {max }}\right)$, Mean Precipitation Rate $(\langle i\rangle)$ Only for Pixels With Precipitation and Percentage of Profiles With Precipitation $\left(F_{i}\right.$ in Percent) OF TYPe $i$, Where $i$ Is RAIN $\langle R\rangle$, GRAUPEL $\langle G\rangle$, AND SNOW $\langle S\rangle$

\begin{tabular}{|c|c|c|c|c|c|c|c|c|c|c|c|c|}
\hline Case & Type & $\begin{array}{c}T \\
U T C\end{array}$ & $N$ & $\begin{array}{c}R_{\max } \\
\mathrm{mmh}^{-1}\end{array}$ & $\begin{array}{l}<R> \\
\mathrm{mmh}^{-1}\end{array}$ & $\begin{array}{c}f_{\text {rain }} \\
\% \\
\end{array}$ & $\begin{array}{r}G_{\max } \\
\mathrm{kgm}^{-2}\end{array}$ & $\begin{array}{l}<G> \\
\mathrm{kgm}^{-2}\end{array}$ & $\begin{array}{c}f_{\text {grau }} \\
\% \\
\end{array}$ & $\begin{array}{c}S_{\max } \\
\mathrm{kgm}^{-2} \\
\end{array}$ & $\begin{array}{l}<S> \\
\mathrm{kgm}^{-2}\end{array}$ & $\begin{array}{c}f_{\text {snow }} \\
\% \\
\end{array}$ \\
\hline \multirow{2}{*}{$\begin{array}{l}\text { Algiers flood } \\
10 \text { Nov } 2001\end{array}$} & \multirow{2}{*}{ convective } & 2 & 28688 & 130.8 & 0.39 & 23 & 24.0 & 0.14 & 51 & 2.5 & 0.18 & 61 \\
\hline & & 7 & 28301 & 107.2 & 0.44 & 29 & 18.7 & 0.14 & 67 & 2.5 & 0.22 & 73 \\
\hline \multirow{2}{*}{$\begin{array}{c}\text { Elbe flood } \\
12 \text { Aug } 2002\end{array}$} & \multirow{2}{*}{$\begin{array}{c}\text { frontal/ } \\
\text { convective }\end{array}$} & 6 & 25459 & 35.7 & 0.41 & 49 & 8.0 & 0.06 & 44 & 2.1 & 0.15 & 56 \\
\hline & & 18 & 25020 & 13.1 & 0.23 & 52 & 4.0 & 0.02 & 42 & 2.0 & 0.07 & 58 \\
\hline \multirow{2}{*}{$\begin{array}{c}\text { Hoek light prec. } \\
19 \text { Sep } 2001\end{array}$} & \multirow{2}{*}{ stratiform } & 3 & 25600 & 9.5 & 0.15 & 37 & 2.6 & 0.01 & 36 & 1.7 & 0.05 & 44 \\
\hline & & 18 & 25519 & 7.7 & 0.22 & 50 & 2.0 & 0.02 & 45 & 1.7 & 0.09 & 67 \\
\hline \multirow{2}{*}{$\begin{array}{l}\text { Rhine winter } \\
10 \text { Feb } 2000\end{array}$} & \multirow{2}{*}{ stratiform } & 9 & 25285 & 16.1 & 0.26 & 42 & 3.6 & 0.04 & 49 & 1.9 & 0.13 & 74 \\
\hline & & 18 & 25571 & 7.3 & 0.28 & 37 & 1.3 & 0.03 & 59 & 1.6 & 0.16 & 81 \\
\hline \multirow{2}{*}{$\begin{array}{l}\text { UK Mill. storm } \\
30 \text { Oct } 2000\end{array}$} & \multirow{2}{*}{ frontal } & 6 & 28404 & 212.5 & 0.5 & 72 & 3.2 & 0.08 & 69 & 2.1 & 0.19 & 83 \\
\hline & & 9 & 28474 & 147.2 & 0.48 & 75 & 5.2 & 0.07 & 72 & 2.1 & 0.17 & 83 \\
\hline
\end{tabular}

the channels at the outer wing of absorption lines. Therefore, the correlations of all channels to the integrated hydrometeor content for all, ocean and land pixels are shown in Fig. 4. A separation into land and ocean pixels reveals that for frequencies of $176.31 \mathrm{GHz}$ and above, no strong differences between land and ocean are obvious, but that for lower frequencies different mechanisms lead to different correlations. In the most transparent channels, e.g., 50.3 and $89 \mathrm{GHz}$, the correlation over ocean is positive for all hydrometeor types, showing the emission effect over the radiatively cold sea (emissivity $\approx 0.5$ ). Over land with its emissivity of about 0.9 , low-level water clouds are still radiatively warmer than the surface, leading to a positive correlation, while frozen hydrometeors, even at low frequencies, already give a negative correlation through the scattering effect. One should be careful in the interpretation of low correlation values $(<0.2)$ at opaque channels $(54.5-$ $55.5 \mathrm{GHz}, 117.25-118.0 \mathrm{GHz}$ ), because the $T_{b}$-variation is very small $(<2 \mathrm{~K})$ and depends mainly on the upper atmospheric pressure distribution, i.e., tropopause height.

The correlation between the surface rain rate and the brightness temperatures is only slightly lower than the one to the rain-water path. The correlation between the integrated rain water and the surface rain rate (see Crewell et al. [44]) has values of at least 0.68 in all simulated cases, and sometimes up to 0.9 . Medium strongly case dependent correlations in the range from 0.3 to 0.7 exist as well between the integrated frozen hydrometeor contents and the surface rain rate. Such a correlation indicates that the surface rain rate can be retrieved through observations at frequencies sensitive to scattering by frozen hydrometeors. This sensitivity can be seen in Fig. 4, where the correlations between brightness temperature and frozen hydrometeors has high negative values up to -0.7 for snow and ice clouds and -0.5 for graupel. As a rule of thumb, the correlation of brightness temperature with surface rain rate or rain-water path is about half of that to snow or ice.

It can clearly be seen from Fig. 4, that the combination of land and ocean pixels reduces the correlation, as different physical processes are mixed. Therefore, it seems sensible to also separate the different regimes, when retrieval algorithms are developed, as the surface flag (land/ocean) is well known.

\section{Retrieval Performance AND FREQUENCY COMBINATIONS}

For each case and for the different surfaces, multiple regression algorithms of the form

$$
q=a+\sum_{i=1}^{n_{\mathrm{tb}}} b_{i} * T_{B_{i}}+\sum_{i=1}^{n_{\mathrm{tb}}} c_{i} * T_{B_{i}}^{2}
$$

For the hydrometeors and the surface rain rate retrieval were developed to evaluate the information content of the particular channel set. Hereby is $q$ the retrieved quantity, $a, b_{i}$, and $c_{i}$ coefficients of the regression, and $T_{B_{i}}$ the simulated brightness temperatures at $n_{\mathrm{tb}}$ frequencies, as mean between horizontal and vertical polarization. By including quadratic terms nonlinearities were taken into account. In the retrieval development, only hydrometeor contents greater than a threshold value of $0.1 \mathrm{~kg} \cdot \mathrm{m}^{-2}$ were considered. The performance in term of relative errors $\delta x$, defined as

$$
\delta x=\frac{\sqrt{\frac{\sum_{n}\left(x_{j}-y_{j}\right)^{2}}{n}}}{\bar{y}} .
$$

The sample standard deviation divided by the mean of the inspected quantity. Hereby is $x_{j}$ the value of the retrieved quantity at pixel $j, y_{j}$ the output of the cloud model for the quantity and pixel, $\bar{y}$ the mean and $n$ the number of all pixels containing the concerned quantity. The results for the relative errors are compiled in Fig. 5. It clearly shows that the performance for ocean and land pixels is different from case to case. Furthermore, it shows that the combination of ocean and land pixels gives worse results particularly in cases with good retrieval potential, e.g., the Hoek case. This emphasizes the importance of separating land and ocean pixels and developing separate algorithms for both conditions. Also, the combination of different cases and time steps leads in general to a reduced performance. For instance, in the HOE1, case the rain-water path for ocean pixels can be retrieved with a relative error of $6.8 \%$, but can increase up to $34.3 \%$ for the ELB1 case. The combination of both surface types and all cases leads to a relative error of $65 \%$. Generally, the graupel water path can be 

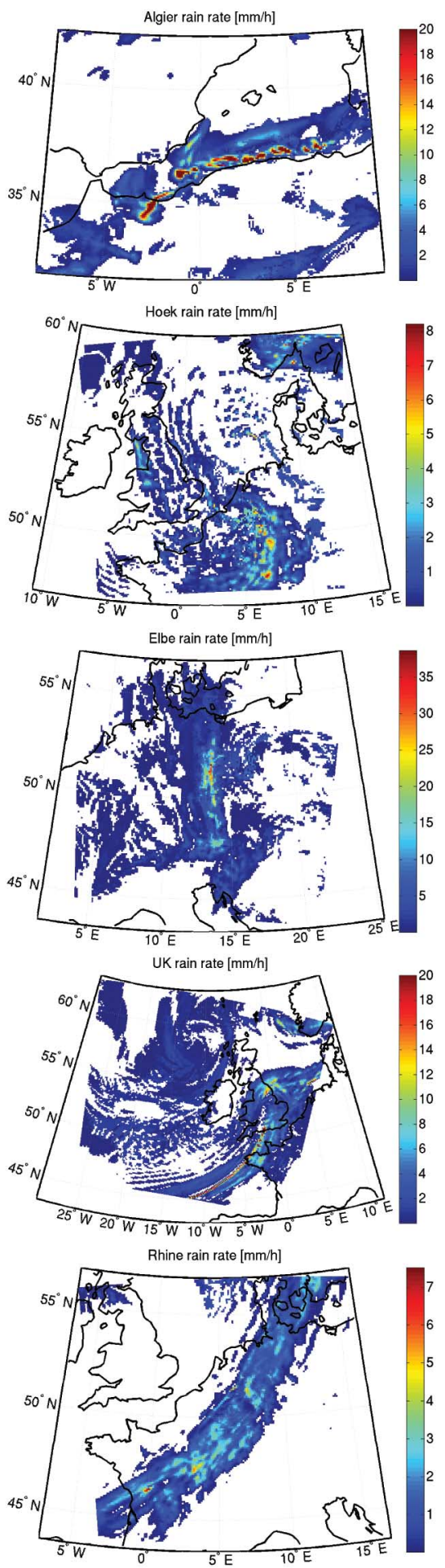

Fig. 1. Overview of the different precipitation cases in terms of surface rain rates (in millimeters per hour) and the respective domains considered in this paper. In the U.K. and Algiers cases, the surface rain rates are shown with a cut off above $20 \mathrm{~mm} / \mathrm{h}$ for presentation reasons. For statistics of the events see Table II.

retrieved with low relative errors of less than $25 \%$ for almost all cases and conditions, as long as separate cases are considered. This is surprising since the very high graupel contents in the Algiers flood case (see Table II) caused high errors in the retrieval, when experimenting with linear regression algorithms.
The snow water path is better detected over land for the more stratiform cases (Hoek, Rhine, and United Kingdom Millenium storm). For the strong convective ALG2 case, the results for the ocean pixels are better. The low relative errors for the frozen hydrometeor types indicate the potential to sense more information about microphysics than just the surface rain rate as an end product. Nevertheless, the good retrieval results on the basis of the simulated database indicate a high potential for retrievals. Results for satellite measurements are likely to have greater relative errors than shown here since there are many more unknowns in the retrieval development, such as particle shape, subscale variability, observation errors, etc.

To test the robustness of the retrieval results on perturbations of the brightness temperatures at all frequencies, common to realistic measurements, random noise with increasing maximum amplitudes up to $2 \mathrm{~K}$ was added to the brightness temperature data set. An investigation of the development of the relative errors while increasing the noise showed, that the increment does not exceed two percentage points, which indicates a high robustness with respect to such disturbances.

Since for a geostationary orbit only frequencies higher than $150 \mathrm{GHz}$ result in spatial resolutions sufficient for numerical weather forecast models and hydrological applications for realistic antenna sizes of $3 \mathrm{~m}$ (i.e., $24 \mathrm{~km}$ at $183 \mathrm{GHz}, 12 \mathrm{~km}$ at $380 \mathrm{GHz}$, and $425 \mathrm{GHz}$ at $10 \mathrm{~km}$ ), retrieval algorithms based on the brightness temperatures simulated at frequencies of $150 \mathrm{GHz}$ and above were developed. By comparing the relative errors of the retrievals based on all frequencies (Fig. 6) to the one based only on the higher ones, the loss in retrieval accuracy by excluding the information contained in the lower frequencies can be clearly seen. As expected, the integrated contents of the frozen hydrometeor types can be retrieved with only a small loss of accuracy, by only using the high frequencies. An exception herein are the very high graupel water paths produced in the strong convective Algiers flood case. For the rain-water path, the consideration of the lower frequencies is important. Omitting the lower frequencies can result in worst cases to a doubling of the relative errors.

Algorithms were also derived for a reduced number of frequencies without considering the provided spatial resolution from geostationary orbits, with the aim to investigate whether window frequencies or absorption channels have a higher potential for precipitation retrieval. The procedure started with finding the frequency channel with the highest correlation and then successively adding further channels, which reduced the relative error most strongly. It needs to be noted, that sometimes the differences in performance between certain channels are very small. Therefore, it is possible that one frequency gives the strongest increase in correlation but another leads to a stronger reduction of the rms.

Depending on whether one considers rain-water path or the surface rain rate, land or ocean pixels, different frequencies provide the most valuable information. The results for a retrieval based on the five most important frequencies in comparison to the one based on all frequencies is shown in Table III. Over the cold ocean the rain-water path is directly related to the emission at frequencies along the wing of the oxygen line. The lowest frequency (e.g., $110.65 \mathrm{GHz}$ ) can be considered as a window 

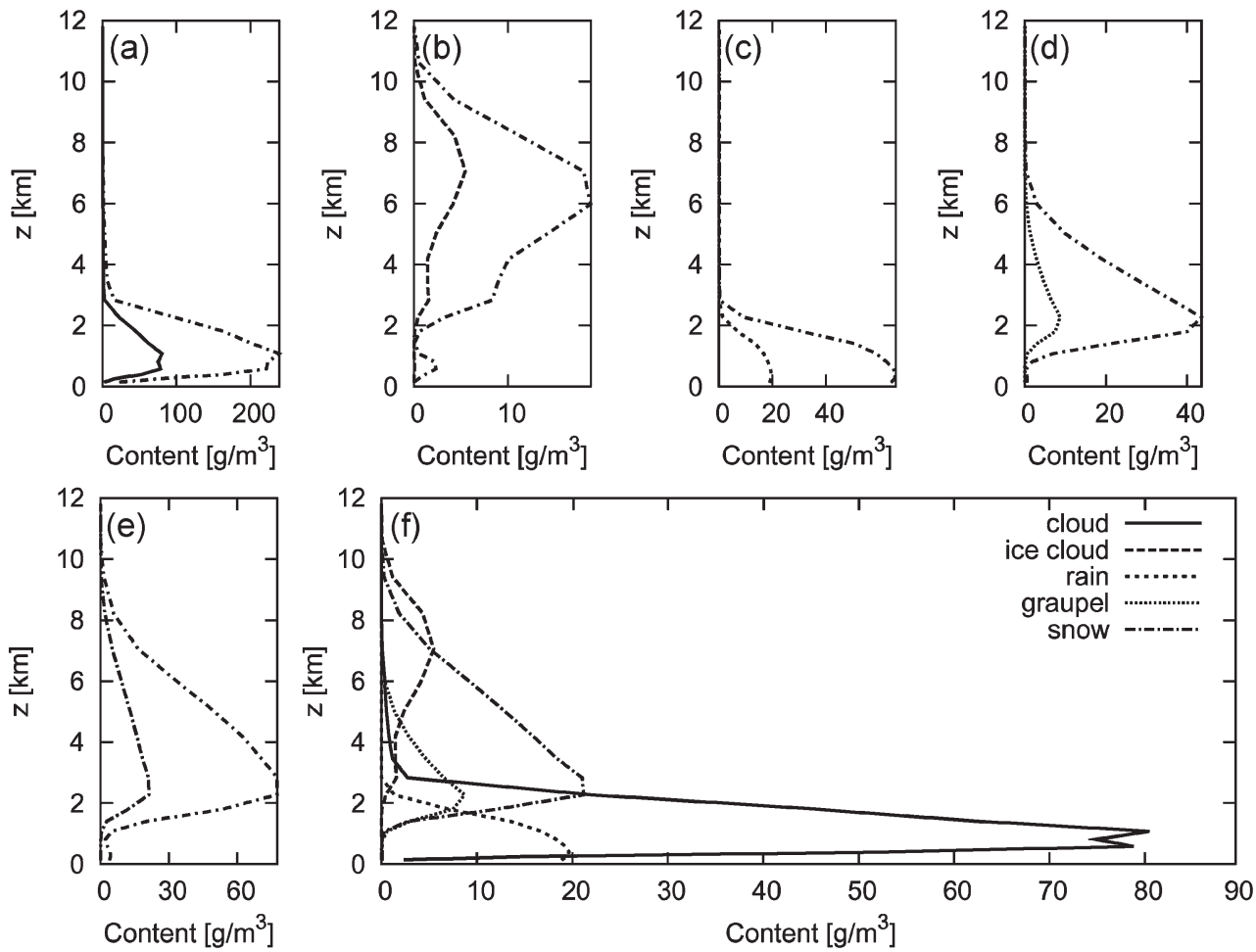

Fig. 2. Mean vertical distribution of the different hydrometeor species in the troposphere for the Hoek case. The figures show the contents in $\mathrm{g} \cdot \mathrm{m}^{-3}$ of (a) water cloud, (b) ice cloud, (c) rain, (d) graupel, and (e) snow. The dashed dotted line represents the respective standard deviation. In figure (f), the contents for all hydrometeor types are compiled together.
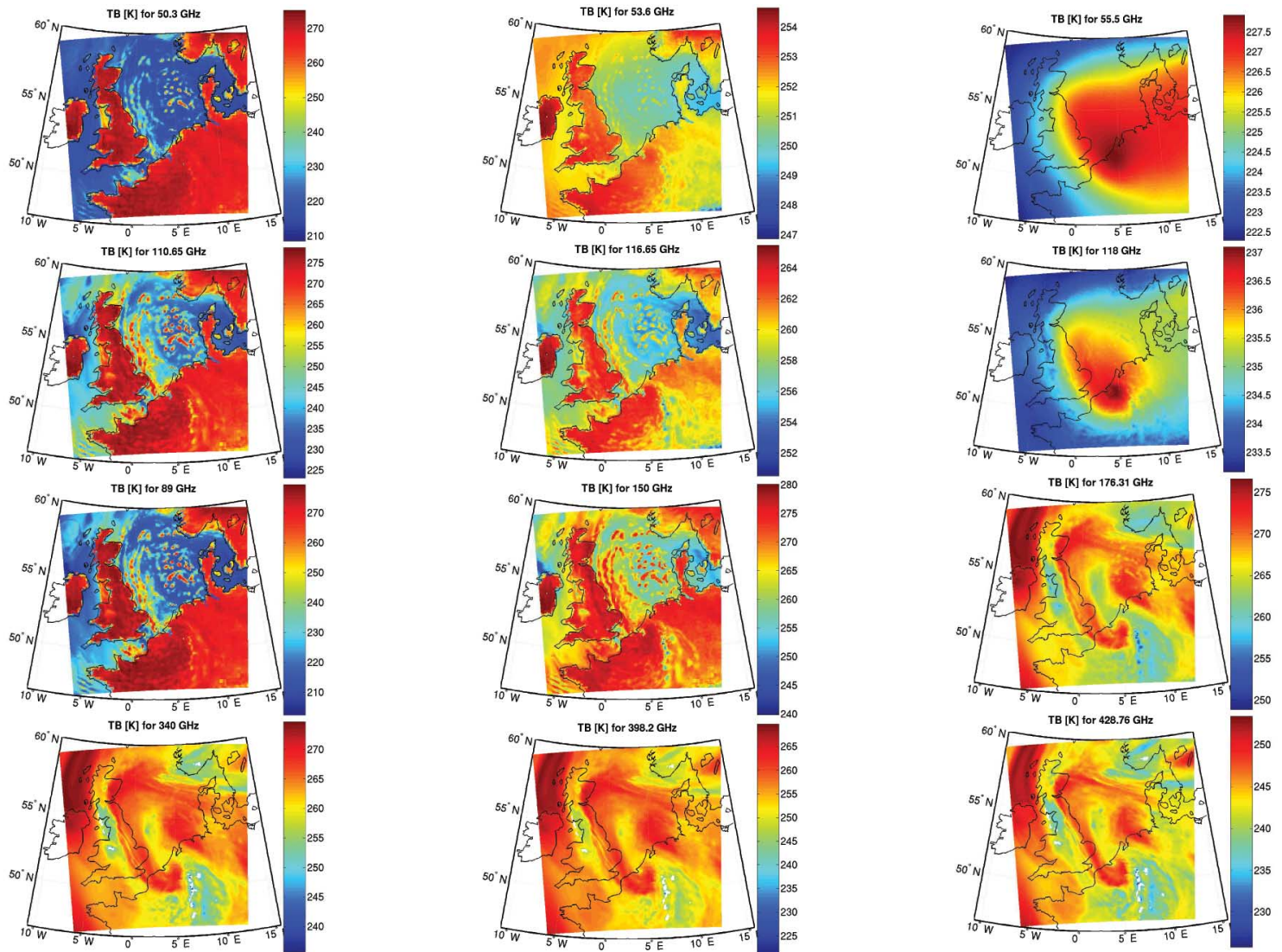

Fig. 3. Horizontal distribution of simulated brightness temperatures for selected frequencies for the Hoek van Holland case on the September 11, 2001 at 18 universal time coordinated. Upper row show simulations for frequencies in the oxygen complex between 50 and $60 \mathrm{GHz}$, second row in the oxygen band at $118 \mathrm{GHz}$, third row at window frequencies 89,150 , and $176.31 \mathrm{GHz}$, and lowest row at higher window frequencies $340,398.2$, and $428.76 \mathrm{GHz}$ on the wing of the 424.76-GHz oxygen line. 

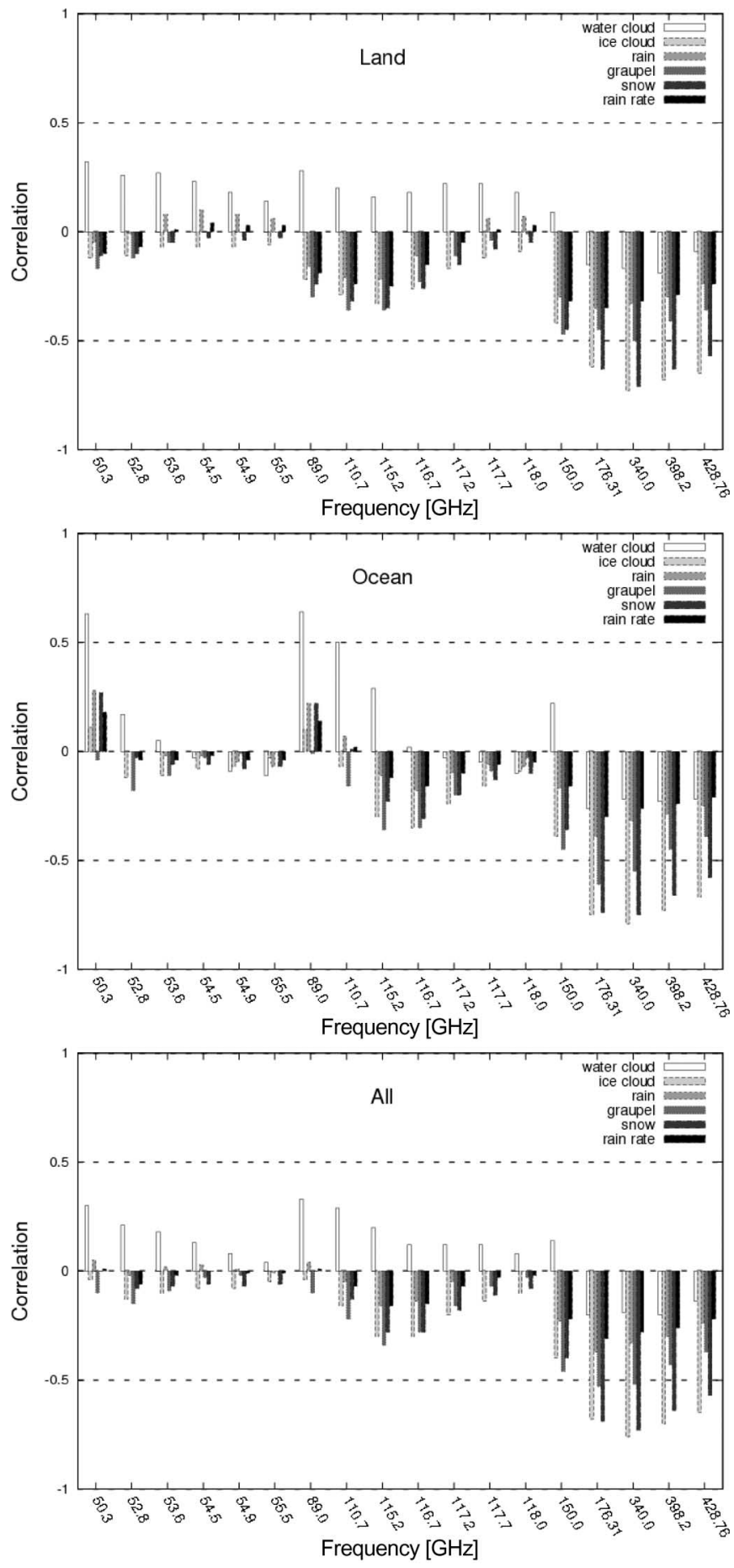

Fig. 4. Correlation between the simulated brightness temperatures at different frequencies and the integrated hydrometeor contents, as well as the surface rain rate, separated into land and ocean pixels and all pixels merged together.

channel. At this frequency, the emission signal is not disturbed by the ice particle scattering as this plays a minor role at these frequencies (see Fig. 4). Therefore, for the rain-water path retrieval lower frequencies in the wings of the oxygen complex provide the most information, with additional information content in the lower window channels (i.e., 89 and $110.65 \mathrm{GHz}$ ). For the land surfaces higher frequencies are favored as additional frequencies, since they are less influenced by the surface emissivity. When the surface rain rate is considered instead of just water column, the higher window frequencies (340 and $150 \mathrm{GHz}$ ) become more important, because they are more strongly related to the ice phase and the whole precipitation process. Over land the $150-\mathrm{GHz}$ channel proves to be most valuable, as well for the surface rain rate, but also channels $>300 \mathrm{GHz}$ appear. Furthermore, the inclusion of channels along the $118-\mathrm{GHz}$ oxygen absorption line is very beneficial, as they also provide information on the temperature and thus, vertical position of the hydrometeors.

For the development of statistical retrieval algorithms, the database serving as a basis for the development needs to encompass the same diversity and variability as the measurements the retrieval algorithms should be applied to. The necessity of a large variability can be clearly seen in Fig. 7, where the data sets were separated into a large training part (four of five cases; both times steps) and a small test part (one case; both time steps). In the next step, retrieval algorithms for land, ocean, and all pixels together were developed with the training data set. Based on the derived coefficients, the retrieval was applied to the test case. This procedure was performed for every simulated case (Fig. 7). For all hydrometeor types in the Algiers flood case, the integrated amounts cannot be retrieved by any means. Their relative errors reach values in the thousands percentages even though, the self-test for the training data sets are not worse than in the other cases. This is caused by the high number of hydrometeors occurring in the Algiers flood case. This variability, with values up to 24 and $2.5 \mathrm{~kg} \cdot \mathrm{m}^{-2}$ for the maximum graupel and snow water paths, is not included in the training set, when the Algiers case is excluded. It is furthermore a good example for the failure of the database if it is not encompassing. The same holds for the graupel and snow water paths over land in the Elbe case. Apart from these outliers and based on this simulated database, the frozen hydrometeor amounts of the various cases can be retrieved quite well by algorithms based on a subset of the database. For the rainwater path retrievals, the self-tests of the training data sets result in relative errors around $50 \%$, which is similar to the one for all cases in Fig. 5. The algorithms applied to the test data sets produce worse results and cause a doubling of the relative errors in some cases. The retrieval of the surface rain rate has already large relative errors in the development stage, but does not show a remarkable increase from the development to the test stage.

\section{Summary AND CONCLUSION}

Current forecast models contain hydrometeor contents as prognostic parameter, but no current technology can provide observations for their verification. Because many microphysical processes are highly parameterized, millimeter wave satellite observations could provide important information to better constrain those parameters. Through the coupling of Méso-NH and the radiative transfer model MWMOD, a tool was created to simulate satellite observations for the millimeter and submillimeter wavelength region. That this model framework results in reasonable simulations was thoroughly analyzed in comparison with infrared and AMSU observations in 

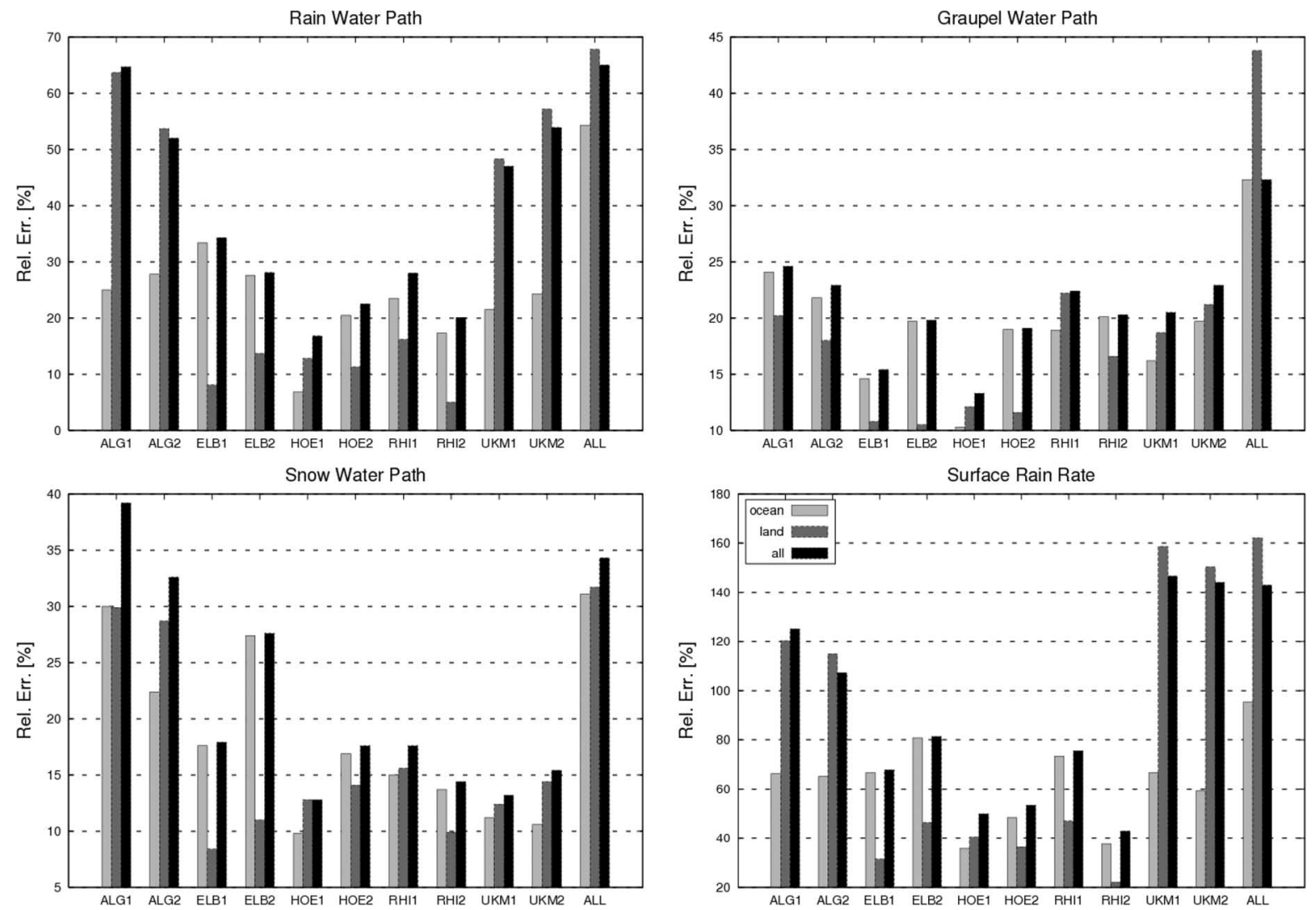

Fig. 5. Relative errors of the retrieval are shown for rain, snow, and graupel water path, as well as for the surface rain rate. The relative errors are separated into land, ocean and all pixels for each single case and time step. The columns indicated by All represent the retrieval performance for all cases and time steps merged together.
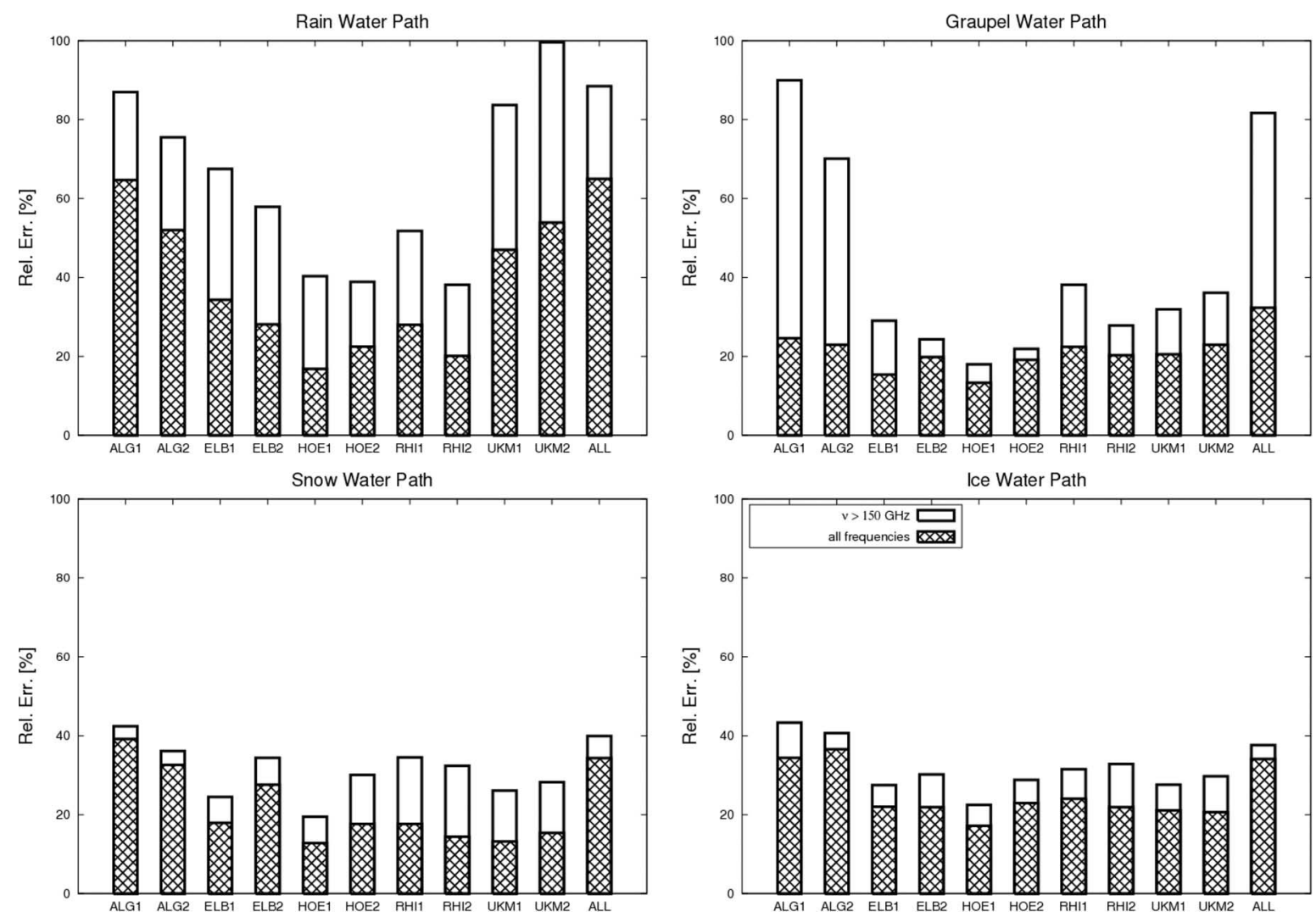

Fig. 6. Comparison of the performance in terms of relative errors between hydrometeor retrievals, including all frequencies and the one based on algorithms, including only frequencies at $150 \mathrm{GHz}$ and above for land and ocean surface types together. 
TABLE III

Performance of Rain-Water Path and Rain Rate Retrieval in Terms of Correlations, Relative ERrors, and RMS for a

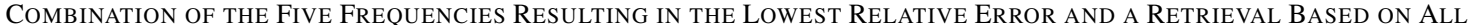
Frequencies. The Five Frequencies Are Ordered With Decreasing IMPORTANCE

\begin{tabular}{|c|c|c|c|c|c|c|}
\hline Quantity & \multicolumn{5}{|c|}{ rain water path } \\
\hline Pixels & \multicolumn{2}{|c|}{ all } & ocean & land \\
\hline Frequencies & $\begin{array}{c}110.65,53.60,52.80, \\
89.0,118.0\end{array}$ & all & $\begin{array}{c}110.65,53.60,52.80, \\
117.65,89.0\end{array}$ & all & $\begin{array}{c}115.25,50.30,176.31, \\
118.0,150.0\end{array}$ & all \\
\hline Correlation & 0.73 & 0.80 & 0.85 & 0.85 & 0.65 & 0.79 \\
\hline Rel. Err. [\%] & 74 & 65 & 54 & 54 & 84 & 68 \\
\hline RMS [kgm ${ }^{-2}$ ] & 0.26 & 0.23 & 0.18 & 0.18 & 0.32 & 0.26 \\
\hline
\end{tabular}

\begin{tabular}{|c|c|c|c|c|c|c|}
\hline Quantity & \multicolumn{5}{|c|}{ rain rate } \\
\hline Pixels & \multicolumn{2}{|c|}{ all } & \multicolumn{2}{c|}{ ocean } & \multicolumn{2}{c|}{ land } \\
\hline Frequencies & $\begin{array}{c}150.0,117.25,340.0, \\
176.31,50.3\end{array}$ & all & $\begin{array}{c}110.65,340.0,117.65, \\
150.0,176.31\end{array}$ & all & $\begin{array}{c}150.0,50.30,176.31, \\
117.65,398.2\end{array}$ & all \\
\hline Correlation & 0.62 & 0.67 & 0.74 & 0.8 & 0.59 & 0.64 \\
\hline Rel. Err. [\%] & 152 & 143 & 105 & 95 & 170 & 162 \\
\hline RMS [mmh ${ }^{-1}$ ] & 2.54 & 2.39 & 1.53 & 1.38 & 3.29 & 3.14 \\
\hline
\end{tabular}
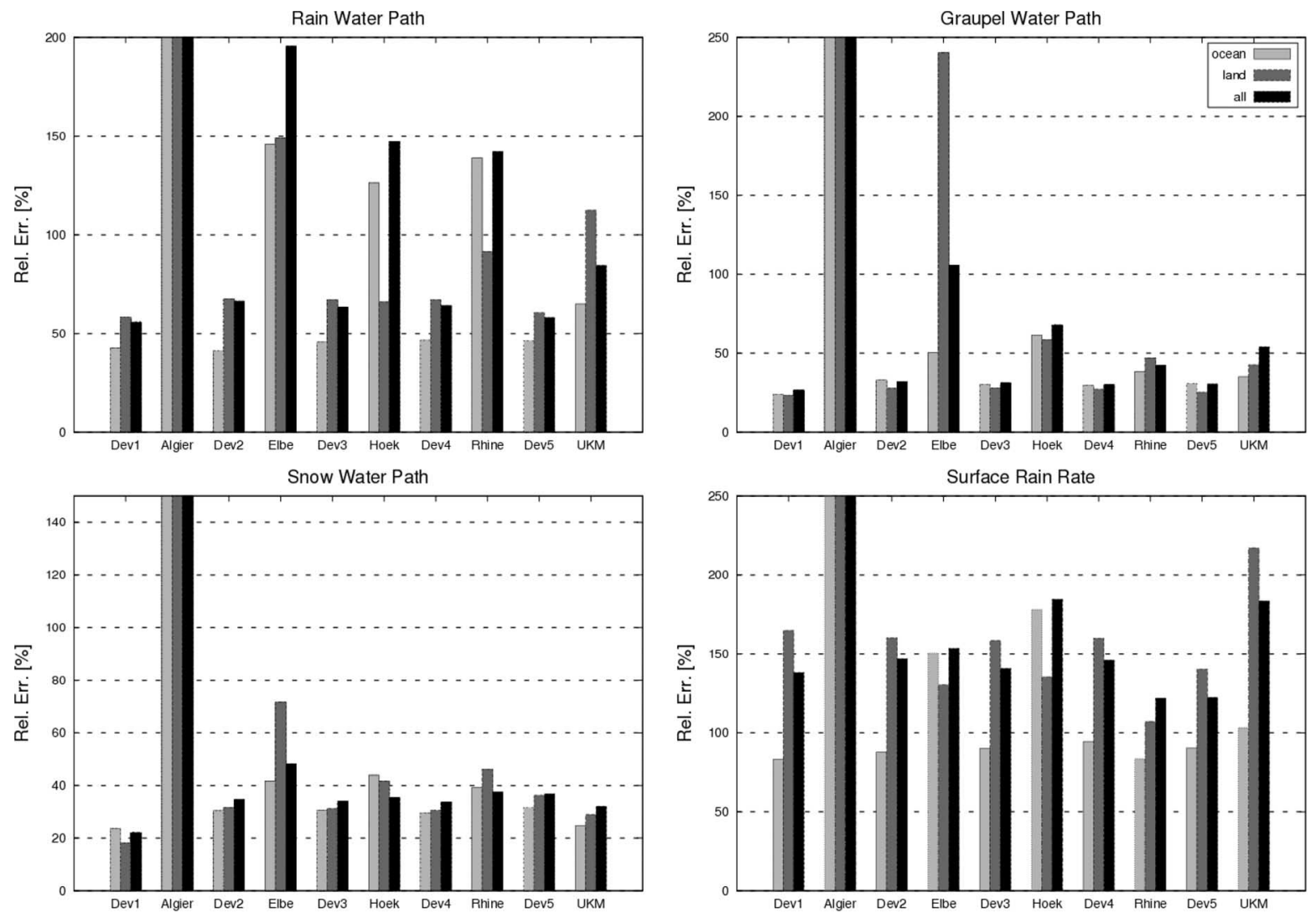

Fig. 7. Shown are tests of the representativeness of the database for rain-water path, graupel water path, snow water path and surface rain rate. Dev1, Dev2, Dev3, Dev4, and Dev5 are the training data sets for the retrieval development built by excluding the case shown to the right of it. The resulting coefficients are applied to retrieve the amounts of the actual quantities of the excluded case. Their performance is the shown in terms of relative errors. For the Algiers flood case, the relative errors are truncated.

Meirold-Mautner et al. [27]. The five simulated mid-latitude precipitation events, described in Section III, resulted in approximately 250000 atmospheric profiles for the forward modeling to achieve brightness temperatures at 18 frequencies for a set of nine zenith angles. The hydrometeor profiles, together with the corresponding brightness temperatures, assemble a unique database for the mid-latitudes, with ample informa- tion content for the estimation of the potential of precipitation observations in the millimeter- and submillimeter-wave region.

The first conclusion to be drawn from analyzing the database is indeed the potential of millimeter and submillimeter wavelengths to sense atmospheric hydrometeors. In particular for graupel and snow high correlations $(>0.9)$ and good 
retrieval accuracies $(<40 \%)$ are achieved, even with simple multiple regression algorithms. For these hydrometeor types, even with algorithms based only on frequencies larger than $150 \mathrm{GHz}$, good retrieval results can be achieved, except in the case of strong convective activity. The performance for the rain-water path and surface rain rate is lower: For convective situations (for example the Algiers case), relative errors in surface rain rate can exceed $100 \%$, while some for stratiform cases (for example the Hoek case) much better results (50\%) are achieved. It should be noted that these are idealized studies not taking into account a number of potential error sources, such as particle shape, subscale variability, and observation errors. They do not reflect realistic satellite retrievals. Nevertheless the results have to be considered in comparison to alternative observation measurements, e.g., ground-based weather radar, with widespread use of polarimetric radar being the only other method to obtain information about the various precipitating hydrometeors (snow, graupel, rain).

The surface emissivity plays a role for frequencies lower than $176 \mathrm{GHz}$ and therefore, separate algorithms for land and ocean areas should be developed. Tests of the adaptability have shown that the development database needs to encompass the whole spectrum of the hydrometeor contents and needs to have a large variability to result in acceptable retrieval results. While the database seems to include a broad repertoire of frontal situations, it should be expanded to include more convective cases since these seem to be underrepresented. A general extension of the database would be preferable since the quality of statistical algorithms is strongly dependent on the scope of the underlying database. The good results achieved for specific cases suggest that for the final retrieval approach it might be worthwhile to first classify the situation to isolate different regimes. A retrieval for the specific regimes could be developed adapted to the conditions in that regime. Such a classification acts like a prelinearization and therefore reduces the number of the possible solutions of the inversion problem. For example a discrimination between stratiform/convective situations or liquid/solid precipitation could be performed prior to any quantitative precipitation retrieval, using the set of available brightness temperatures. The algorithm developed for specific conditions does not have to account for variability observed under other conditions and as a consequence is more constrained.

The retrieval potential for the different hydrometeor types achieved under the constraints of the simulated database indicates that microwave satellite observations could play an important role in evaluating the performance of numerical weather prediction models in the future. For example, graupel and snow are prognostic model parameters, and essential parameters in the cloud schemes determining in the end forecast precipitation rate at the ground. To date no wide-area observations of such parameters are available for further improvement of the cloud schemes.

\section{ACKNOWLEDGMENT}

The authors would like to thank U. Löhnert for insights regarding retrieval development.

\section{REFERENCES}

[1] P. M. Austin, "Relation between measured radar reflectivity and surface rainfall," Mon. Weather Rev., vol. 115, no. 5, pp. 1053-1070, May 1987.

[2] T. T. Wilheit, A. T. C. Chang, M. S. V. Rao, E. B. Rodgers, and J. S. Theon, "A satellite technique for quantitatively mapping rainfall rates over oceans," J. Appl. Meteorol., vol. 16, no. 5, pp. 551-560, May 1977.

[3] C. Prabhakara, G. Dalu, G. L. Liberti, J. J. Nucciarone, and R. Suhasini, "Rainfall estimation over ocean from SSMR and SSM/I microwave data," J. Appl. Meteorol., vol. 31, no. 6, pp. 532-551, Jun. 1992.

[4] P. Bauer and P. Schlüssel, "Rainfall, total water, ice water, and water vapour over sea from polarized microwave simulations and special sensor microwave/imager data," J. Geophys. Res., vol. 98, no. D11, pp. $20737-$ $20759,1993$.

[5] E. A. Smith, C. D. Kummerow, and A. Mugnai, "The emergence of inversion-type profile algorithms for estimation of precipitation from satellite passive microwave measurements," Remote Sens. Rev., vol. 11, pp. 211-242, 1994.

[6] C. Kummerow, W. S. Olson, and L. Giglio, "A simplified scheme for obtaining precipitation and vertical hydrometeor profiles from passive microwave sensors," IEEE Trans. Geosci. Remote Sens., vol. 34, no. 5, pp. 1213-1232, Sep. 1996

[7] R. W. Spencer, H. M. Goodman, and R. E. Hood, "Precipitation retrieval over land and ocean with the SSM/I: Identification and characteristics of the scattering signal," J. Atmos. Ocean. Technol., vol. 6, no. 2, pp. 254 $273,1989$.

[8] N. C. Grody, "Classification of snow cover and precipitation using the special sensor microwave imager," J. Geophys. Res., vol. 96, no. D4, pp. 7423-7435, 1991.

[9] R. R. Ferraro, F. Weng, N. C. Grody, and A. Basist, "An eight-year (1987-1994) time series of rainfall, clouds, water vapour, snow cover, and sea ice derived from SSM/I measurements," Bull. Amer. Meteorol. Soc., vol. 77, no. 5, pp. 891-905, May 1996.

[10] C. Kidd, "On rainfall retrieval using polarization-corrected temperatures," Int. J. Remote Sens., vol. 19, no. 5, pp. 981-996, Mar. 1998.

[11] M. D. Conner and G. W. Petty, "Validation and intercomparison of SSM/I rain-rate retrieval methods over the continental United States," J. Appl. Meteorol., vol. 37, no. 7, pp. 670-700, 1998.

[12] P. Bauer, D. Burose, and J. Schulz, "Rain detection over land surfaces using passive microwave satellite data," Meteorol. Z., vol. 11, no. 1, pp. 37-48, Jan. 2002.

[13] A. J. Gasiewski, "Numerical sensitivity analysis of passive EHF and SMMW channels to tropospheric water vapor, clouds, and precipitation," IEEE Trans. Geosci. Remote Sens., vol. 30, no. 5, pp. 859-870, Sep. 1992.

[14] K. F. Evans, S. J. Walter, A. J. Heymsfield, and M. N. Deeter, "Modeling of sub-millimeter passive remote sensing of cirrus clouds," J. Appl. Meteorol., vol. 37, no. 2, pp. 184-205, Feb. 1998.

[15] P. Bauer and A. Mugnai, "Precipitation profile retrievals using temperature-sounding microwave observations," J. Geophys. Res., vol. 108 , no. D23, p. 4730, 2003.

[16] A. J. Gasiewski, J. W. Barrett, P. G. Bonanni, and D. H. Staelin, "Aircraftbased radiometric imaging of tropospheric temperature and precipitation using the 118.75-GHz oxygen resonance," J. Appl. Meteorol., vol. 29, no. 7, pp. 620-632, Jul. 1990.

[17] A. J. Gasiewski and D. H. Staelin, "Numerical modeling of passive microwave $\mathrm{O}_{2}$ observations over precipitation," Radio Sci., vol. 25, no. 3, pp. 217-235, 1990 .

[18] D. H. Staelin and F. W. Chen, "Precipitation observations near 54 and $183 \mathrm{GHz}$ using the NOAA-15 satellite," IEEE Trans. Geosci. Remote Sens., vol. 38, no. 5, pp. 2322-2332, Sep. 2000.

[19] E. A. Smith, A. Mugnai, H. J. Cooper, G. J. Tripoli, and X. Xiang, "Foundation for statistical-physical precipitation retrieval from passive microwave satellite measurements. Part I: Brightness-temperature properties of a time-dependent cloud-radiation model," J. Appl. Meteorol., vol. 31, no. 6, pp. 506-531, Jun. 1992.

[20] C. Kummerow and L. Giglio, "A passive microwave technique for estimating rainfall and vertical structure information from space. Part I: Algorithm description," J. Appl. Meteorol., vol. 33, no. 1, pp. 3-18, Jan. 1994.

[21] A. Mugnai, "EGPM-The proposed European contribution to the global precipitation measurement (GPM) mission," Geophys. Res. Abstr., vol. 5, p. $12550,2003$.

[22] P. Bauer, E. Moreau, and S. D. Michele, "Hydrometeor retrieval accuracy using microwave window and sounding channel observations," J. Appl. Meteorol., vol. 44, no. 7, pp. 1016-1032, Jul. 2005. 
[23] J.-P. Lafore, J. Stein, N. Asencio, P. Bougeault, V. Ducrocq, J. Duron, C. Fischer, P. Héreil, P. Mascart, V. Masson, J.-P. Pinty, J.-L. Redelsperger, E. Richard, and J. V.-G. de Arellano, "The Méso-NH atmospheric simulation system. Part I: Adiabatic formulation and control simulations," Ann. Geophys., vol. 16, no. 1, pp. 90-109, 1998.

[24] J.-P. Chaboureau, J.-P. Cammas, P. Mascart, J.-P. Pinty, C. Claud, R. Roca, and J.-J. Morcrette, "Evaluation of a cloud system life-cycle simulated by the Méso-NH model during FASTEX using METEOSAT radiances and TOVS-3I cloud retrievals," Q. J. Roy. Meteorol. Soc., vol. 126, no. 566, pp. 1735-1750, Jul. 2000 .

[25] J.-P. Chaboureau, J.-P. Cammas, P. Mascart, J.-P. Pinty, and J.-P. Lafore, "Mesoscale model cloud scheme assessment using satellite observations," J. Geophys. Res., vol. 107, no. D16, p. 4301, 2002.

[26] J.-P. Chaboureau, N. Sohne, J. P. Pinty, I. Meirold-Mautner, E. Defer, C. Prigent, M. Mech, and S. Crewell, "A midlatitude precipitating cloud database validated with satellite observations," J. Appl. Meteorol. Clim., 2007. submitted for publication.

[27] I. Meirold-Mautner, C. Prigent, J.-R. Pardo, J.-P. Chaboureau, J.-P. Pinty, M. Mech, and S. Crewell, "Radiative transfer simulations using mesoscale cloud model outputs: Comparisons with passive microwave and infrared satellite observations for mid-latitude situations," J. Atmos. Sci., 2007. in press.

[28] M. Wiedner, C. Prigent, J.-R. Pardo, O. Nuissier, J.-P. Chaboureau, J.-P. Pinty, and P. Mascart, "Modeling of passive microwave responses in convective situations using output from mesoscale models: Comparison with TRMM/TMI satellite observations," J. Geophys. Res., vol. 109, no. D6, pp. 1-13, 2004

[29] V. Ducrocq, D. Ricard, J. P. Lafore, and F. Orain, "Storm-scale numerical rainfall prediction for five precipitating events over France: On the importance of the initial humidity field,"Weather Forecast., vol. 17, no. 6, pp. 1236-1256, Dec. 2002.

[30] E. Richard, S. Cosma, P. Tabary, J.-P. Pinty, and M. Hagen, "Highresolution numerical simulations of the convective system observed in the Lago Maggiore area on 17 September 1999 (MAP IOP 2a)," Q. J. Roy. Meteorol. Soc., vol. 129, no. 588, pp. 543-563, 2003.

[31] J.-P. Pinty and P. Jabouille, "A mixed-phase cloud parameterization for use in a mesoscale non-hydrostatic model: Simulations of a squall line and of orographic precipitations," in Proc. AMS Conf. Cloud Phys., 1998.

[32] Y.-L. Lin, R. D. Farley, and H. D. Orville, "Bulk parameterization of snow field in a cloud model," J. Appl. Meteorol., vol. 22, no. 6, pp. 1065-1092, Jun. 1983.

[33] H. Czekala and C. Simmer, "On precipitation induced polarization of microwave radiation measured from space," Meteorol. Z., vol. 11, no. 1, pp. 49-60, Jan. 2002.

[34] H. J. Liebe, G. A. Hufford, and M. G. Cotton, "Propagation modeling of moist air and suspended water/ice particles at frequencies below 1000 GHz," in Proc. AGARD 52nd Spec. Meeting Electromagn. Wave Propag. Panel, Palma de Mallorca, Spain, 1993, pp. 3-1-3-10.

[35] J.-R. Pardo, J. Cernicharo, and E. Serabyn, "Atmospheric transmission at microwaves (atm): An improved model for $\mathrm{mm} / \mathrm{submm}$ applications," IEEE Trans. Antennas Propag., vol. 49, no. 12, pp. 1683-1694, Dec. 2001.

[36] M. I. Mishchenko, L. D. Travis, and D. W. Mackowski, "T-matrix computations of light scattering by non-spherical particles: A review," J. Quant. Spectrosc. Radiat. Transfer, vol. 55, no. 5, pp. 535-575, May 1996.

[37] C. Prigent, W. B. Rossow, and E. Matthews, "Microwave land surface emissivities estimated from SSM/I observations," J. Geophys. Res., vol. 102, no. D18, pp. $21867-21890,1997$.

[38] S. English and T. Hewison, "A fast generic millimeter-wave emissivity model," Proc. SPIE, pp. 288-300, 1998.

[39] T. Manabe, H. J. Liebe, and G. A. Hufford, "Complex permittivity of water between 0 and $30 \mathrm{THz}$," in Proc. 12th IEEE Int. Conf. Infrared and and Millimeter Waves, Orlando, FL, 1987, pp. 229-230.

[40] S. G. Warren, "Optical constants of ice from the ultraviolet to the microwave," Appl. Opt., vol. 23, no. 8, pp. 1206-1225, Apr. 1984.

[41] G. M. Skofronick-Jackson, A. J. Gasiewski, and J. R. Wang, "Influence of microphysical cloud parameterizations on microwave brightness temperatures," IEEE Trans. Geosci. Remote Sens., vol. 40, no. 1, pp. 187-196, Jan. 2002.

[42] C. Melsheimer, C. Verdes, S. A. Bhler, C. Emde, D. G. Feist, S. Ichizawa, V. O. John, Y. Kasai, G. Kopp, N. Koulev, T. Kuhn, O. Lemke, S. Ochiai, F. Schreier, T. R. Sreerekha, M. Suzuki, S. Tsujimaru, and J. Urban, "Intercomparison of general purpose clear sky atmospheric radiative transfer models for the millimeter/submillimeter spectral range," Radio Sci., vol. 40, no. 1, pp. RS1007.1-RS1007.28, 2005.

[43] P. Bauer, J. P. V. P. Baptista, and M. de Iulis, "The effect of the melting layer on the microwave emission of clouds over the ocean," J. Atmos. Sci., vol. 56, no. 6, pp. 852-867, Mar. 1999.
[44] Final report, contract No. EUM/CO/04/1311/KJG., S. Crewell, M. Mech, C. Prigent, I. Meirold-Mautner, J.-P. Chaboureau, J.-P. Pinty, J. Schulz, H. Czekala, D. Feist, and U. Löhnert, Simulation study of precipitating clouds from geostationary orbits with passive microwaves, 2005, Darmstadt, Germany: EUMETSAT. [Online]. Available: http://www. eumetsat.int/groups/pps/documents/document/pdf_mtg_rep20.pdf

[45] G. M. Skofronick-Jackson, M.-J. Kim, J. A. Weinman, and D.-E. Chang, "A physical model to determine snowfall over land by microwave radiometry," IEEE Trans. Geosci. Remote Sens., vol. 42, no. 5, pp. 1047-1058, May 2004.

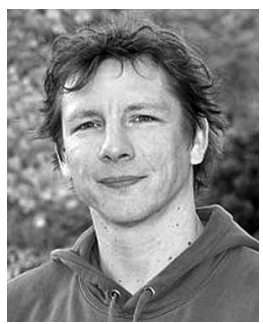

Mario Mech received the Diploma degree in meteorology from the Ludwig-Maximilians University of Munich, Munich, Germany, in 2002, where he is currently working toward the Ph.D. degree.

Since 2007, he has been working as a Research Scientist at University of Cologne, Cologne, North Rhine-Westphalia, Germany. His studies have focused on radiative transfer in the ultraviolet and the impact of receiver inclination on the UV-index. During his $\mathrm{Ph}$.D. studies, he has worked on the radiative transfer in the microwave region and the adaptability of millimeter and submillimeter frequencies for space-borne remote sensing of precipitation observation. Furthermore, he is involved in the development of a database for the single scattering properties of frozen hydrometeors for the millimeter and submillimeter wavelength range.

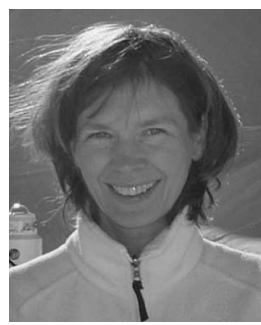

Susanne Crewell (M'06) received the Ph.D. degree in physics from University of Bremen, Bremen, Germany, in 1993.

Since 2004, she has been a Professor of experimental meteorology at the Ludwig-Maximilians University of Munich, Munich, Germany. From 1994 to 1996, she worked at the State University of New York, Stony Brook. Her research interests focus on passive microwave remote sensing of the earth. She has worked on latent heat flux determination from satellite, observation of stratospheric trace gases from aircraft and ground, as well as tropospheric water vapor, temperature, and hydrometeors. Currently, her main interests include the combination of observations in different spectral regions and the use of observations for improving atmospheric weather forecast models.

Dr. Crewell is an Associate Editor of IEEE Geoscience Remote SENSING LETTERS.

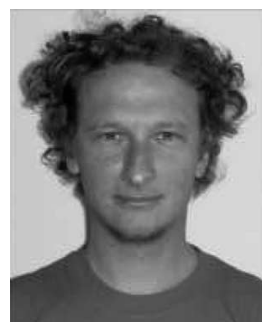

Ingo Meirold-Mautner received the Ph.D. degree in meteorology from University of Innsbruck, Innsbruck, Austria, in 2004.

In his Ph.D. thesis entitled "A physical radiation transfer model for snow: Measurements, model development and application to the snow ecosystem," he analyzed the radiation transfer in snow with a strong focus on snow characteristics. After his Ph.D., he worked as a Postdoc at the l'Observatoire de Paris, France, on passive microwave remote sensing. He compared satellite observations with simulated brightness temperatures, analyzed the influence of particle properties and was involved in the development of retrieval algorithms. 


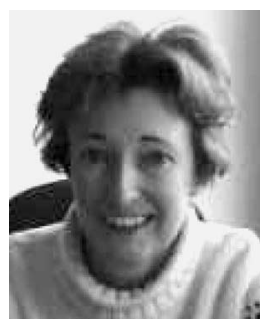

Catherine Prigent received the Ph.D. degree in physics from Paris University, Paris VII, in 1988.

Since 1990, she is a Researcher for the Centre National de la Recherche Scientifique (CNRS) in l'Observatoire de Paris. From 1995 to 2000, she was on leave from the CNRS and she worked at NASA/Goddard Institute for Space Studies, Columbia University, NY. Her research interests focus on passive microwave remote sensing of the earth. Her early work focused on modeling of the sea surface emissivities at microwave wavelengths and the estimation of atmospheric parameters over ocean from microwave measurements. Currently, her main interests include calculation and analysis of microwave land surface emissivities, estimation of atmospheric and surface parameters over land from microwave observations, as well as multisatellite characterization of the land surface. She is also involved in satellite remote sensing of clouds with the analysis of passive microwave observations over convective cloud structures.

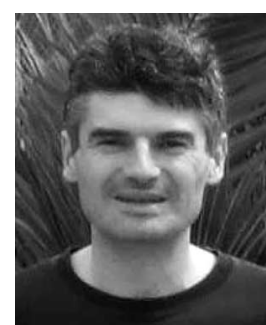

Jean-Pierre Chaboureau received the Ph.D. degree from Ecole Polytechnique, Palaiseau, France, in 1999, and the Habilation à Diriger des Recherches from University Paul Sabatier, Toulouse, France, in 2006 .

He was with the Laboratoire d'Aérologie Université Paul Sabatier/Centre National de la Recherche Scientifique) in 1998, where he is currently Assistant Physicist since 2002. His Ph.D. work focused on atmospheric water vapor and its retrieval from satellite observations. His main research interest is the cloud and rain processes, their representation within the French mesoscale model Méso-NH, and their evaluation using satellite observations. 